Cadernos de Clio, Curitiba, v. 10, $n^{\circ} .2,2019$

\title{
O PASSADO MEDIEVAL, O PRESENTE INDUSTRIAL E UM FUTURO COMUNISTA EM NOTÍCIAS DE LUGAR NENHUM DE WILLIAM MORRIS
}

\section{THE MEDIEVAL PAST, THE INDUSTRIAL PRESENT AND A COMMUNIST FUTURE IN WILLIAM MORRIS' NEWS FROM NOWHERE}

Resumo: O presente trabalho pretende analisar aspectos da utopia comunista em Noticias de Lugar Nenhum, do escritor inglês William Morris, comparando-a com a sociedade industrial do século XIX em que vivia (e em relação à qual sua utopia é diretamente contraposta). Ademais, serão destacados alguns aspectos desta utopia que podem aproximá-la de um passado medieval europeu idealizado pelo autor - configurando, assim, uma comparação entre o presente vitoriano no qual o autor viveu, o futuro comunista que ele imagina, e o passado medieval que ele recupera. Mais especificamente, os aspectos sociais privilegiados nesta análise são a questão do trabalho e do modo de vida (se rural ou urbano).

Palavras-chave: Literatura; Século XIX; William Morris; Notícias de Lugar Nenhum; Socialismo Utópico.

Abstract: This paper intends to analyze aspects of the communist utopia in William Morris' News from Nowhere, comparing it to the 19th century industrial society in which he lived (and to which his utopia is directly opposed to). Furthermore, certain aspects of this utopia that bring it closer to a medieval european past idealized by the author will be pointed out -

\footnotetext{
${ }^{1}$ Graduando em História (Licenciatura e Bacharelado) na Universidade Federal do Paraná desde 2017. Atualmente desenvolve pesquisa na área de História Antiga, especificamente com Roma republicana nos séculos II e I a.C. Email para contato: hugotbeker@gmail.com.
} 
hence resulting in a comparison between the victorian present in which the author lived, the communist future which he imagines, and the medieval past which he revives. Specifically, the social aspects privileged in this analysis are labour and the lifestyle (if rural or urban).

Keywords: Literature; 19th Century; William Morris; News from Nowhere; Utopian Socialism.

\section{Introdução ${ }^{2}$}

Nosso autor nasceu em março de 1834 em Walthamstow, Inglaterra, no seio de uma família burguesa - seu pai era financista na cidade de Londres e sua mãe era professora de música em Worcester. Ingressou no Exeter College (Universidade de Oxford) em 1853, inicialmente tendo a intenção de entrar para a vida clerical. Entretanto, Morris acabou desenvolvendo uma grande admiração pela arquitetura gótica e, depois de ter se graduado em 1856, passou a se dedicar às artes plásticas - tentando, num primeiro momento, aprender arquitetura e, posteriormente e com maior sucesso, se dedicando à decoração de interiores e ao design de tecidos e papéis de parede (sendo inclusive considerado um dos maiores nomes do design industrial). A sua preocupação com a importância da arquitetura e dos edifícios (principalmente os antigos) o levaram a fundar em Londres, juntamente com outros colegas, a Society for the Protection of Ancient Buildings ${ }^{3}$ em 1877.

${ }^{2}$ Neste trabalho, todas as citações de obras em inglês serão traduzidas para o português em tradução livre por nós. Os trechos originais em inglês estarão nas respectivas notas de rodapé.

${ }^{3}$ Em tradução livre: Sociedade pela Proteção de Edificios Antigos. Existente até hoje, trata-se de uma das primeiras sociedades de conservação de patrimônio 
Morris também se dedicou à escrita e à tradução literárias, tendo publicado uma série de obras como os poemas The Earthly Paradise (1868-1870) e Sigurd the Volsung and the Fall of the Niblungs (1876) e os romances A Dream of John Ball (1886) e The Well at the World's End (1892), além de ter traduzido obras clássicas como a Eneida (1876) e, em parceria com um estudioso islandês, as sagas medievais islandesas, posteriormente publicadas em inglês com o título Three Northern Love Stories $(1875)^{4}$. Em 1891, Morris fundou no distrito londrino de Hammersmith a Kelmscott Press, editora especializada na publicação de textos medievais e clássicos da literatura inglesa, além de algumas obras do próprio fundador.

Por fim, também cabe destacar a grande atuação política de William Morris em favor da causa socialista. Em 1883, ele se juntou à Federação Democrática, partido socialista revolucionário liderado por Henry Hyndman. Apenas um ano depois, Morris acabou emergindo (com certa relutância) como o líder da Liga Socialista, grupo que se separou de Hyndman por conta da visão favorável ao parlamentarismo que tinha seu partido. Morris participou e esteve no centro de inúmeros protestos políticos na Grã-Bretanha entre as décadas de 1880 e 1890, inclusive na demonstração de 13 de novembro de 1887, episódio que ficou

material. Cf. SPAB. About us. Disponível em: $<$ https://www.spab.org.uk/about-us $>$. Acesso em: 18 ago 2019.

4 Tradução livre dos títulos em inglês, respectivamente: O Paraíso Terrestre (1868-1870); Sigurd o Volsungo e a Queda dos Nibelungos (1876); Um Sonho de John Ball (1886); O Poço no Fim do Mundo (1892) e Três Histórias de Amor Nortenhas (1875). 
posteriormente conhecido como "domingo sangrento". Apesar de nunca ter abandonado sua atuação e seu posicionamento político, Morris acabou sendo gradativamente afastado do protagonismo na Liga Socialista a partir de 1888, passando a se dedicar novamente à escrita e à sua recém-fundada editora. William Morris faleceu de causas naturais em outubro de 1896, em Londres, aos 62 anos de idade.

News from Nowhere (Notícias de Lugar Nenhum) foi lançado pela primeira vez em 1890, em forma de publicação seriada no The Commonweal, o jornal da Liga Socialista fundado em 1885. Assim, a obra está inserida num contexto em que manifestações populares e movimentos políticos contestavam a ordem burguesa industrial do século XIX e num momento em que o autor já vinha atuando politicamente de forma ativa em reuniões de socialistas e em manifestações públicas. Ademais, trata-se de um contexto em que as indústrias eram já fortemente mecanizadas, a sociedade inglesa era eminentemente urbana e o imperialismo europeu sobre outros continentes já tomava forma - aspectos sociais que serão criticados ao longo da obra.

A narrativa se inicia em Londres, no século XIX, com o protagonista ${ }^{5}$ saindo de uma reunião da Liga Socialista. Na mesma noite, ele tem um

5 O nome do protagonista não nos é revelado em nenhum momento da obra, sendo que os habitantes da Inglaterra socialista com os quais ele interage se referem a ele apenas como "Convidado" (Guest). O narrador do capítulo I nos diz que é um amigo seu quem conhece a história deste personagem, e que, a partir do capítulo II, este mesmo amigo irá narrar, em primeira pessoa, esta história. Portanto, do capítulo II até o fim da obra, a narração é feita por um narrador-personagem e protagonista. 
longo sonho no qual se aventura, de forma vívida, numa Inglaterra comunista do século XXI. Através de observações e interações com esta sociedade e seus habitantes, ele vai conhecendo as suas características e, sobretudo, comparando-a com a sociedade da Era Vitoriana.

\section{Passado, presente e futuro em Notícias de Lugar Nenhum, de William Morris}

A forma através da qual Morris estrutura seu romance é, marcadamente, uma comparação praticamente constante entre o contexto "presente" para o qual o narrador-personagem foi transportado (a Inglaterra no idealizado mundo comunista do século XXI) e o passado daquele contexto - o passado humano como um todo quanto, e principalmente, a Inglaterra do século XIX (contexto em que o protagonista nasceu e viveu). Em outras palavras, o romance é uma comparação entre uma futura Inglaterra comunista do XXI (tempo presente no qual a maior parte do romance se passa) e, sobretudo, a Inglaterra industrial do XIX (tempo pretérito em relação ao contexto em que essa maior parte da obra se passa, apesar de ser a realidade de onde nosso protagonista veio).

Esta comparação se dá, ao longo do livro, de duas principais maneiras: através das observações e dos diálogos em que o narrador-personagem se envolve ao longo de sua estadia naquela realidade, e através da conversa entre ele e o personagem Hammond, um velho sábio que conhece bem a história principalmente da sociedade do século XIX e 
do processo, ao longo do século $\mathrm{XX}$, que levou à constituição daquela nova sociedade.

No primeiro tipo de situação, as comparações entre as duas sociedades são sentidas através da descrição que o protagonista faz das paisagens e das pessoas do local e, principalmente, através das conversas e das interações que ele tem com estas mesmas pessoas. Muitas vezes, estas interações e conversas são marcadas por estranhamentos e desentendimentos, ainda que nosso protagonista tente, salvo algumas exceções, não deixar transparecer que ele veio de um outro período.

No segundo tipo de situação, o personagem Hammond, sendo um grande conhecedor tanto da história do século XIX quanto do século seguinte, é a principal fonte de informação que pode explicar ao narrador-personagem a forma como aquela sociedade estava organizada, como ela se diferencia principalmente da realidade do século XIX e como ela veio a se constituir. Estas explicações são feitas por meio de longos diálogos nos quais predominam críticas de Hammond à organização da sociedade capitalista industrial e comparações diretas entre esta sociedade e a realidade comunista da qual fazia parte.

Ademais, uma análise da caracterização que Morris dá à sua sociedade idealizada nos permite identificar a outra comparação que o autor faz entre um tempo presente e um tempo pretérito: o século XIX em que William Morris viveu comparado com o passado medieval europeu. Isto está relacionado com a própria perspectiva crítica que ele tem em relação ao contexto vitoriano: a partir da biografia de Morris escrita pela 
historiadora cultural Fiona MacCarthy, vemos que ele percebia os inúmeros problemas e injustiças sociais de seu período mesmo antes de se juntar à Federação Democrática, em 1883 (ato considerado a sua declaração aberta em favor da causa socialista). Também a partir desta biografia percebemos que Morris teve, desde a infância e até o fim da vida, uma paixão pelo medievo europeu e pela literatura (principalmente as obras clássicas e medievais): "Ele foi um leitor precoce, afirmando ter começado as obras de Sir Walter Scott aos quatro anos de idade e ter concluído todo o conjunto aos sete. Desde já ele era muito receptivo ao medievalismo e romance" (MACCARTHY, 2009: 2) ${ }^{6}$.

Esta admiração por aspectos do passado medieval fica evidente no próprio romance, na medida em que Morris dá à sua Inglaterra comunista uma caracterização com uma série de aspectos que podem ser considerados como típicos do medievo europeu - a predominância de uma população do campo e a sobreposição de um estilo de vida rural mesmo sobre os habitantes dos antigos centros urbanos, a preferência pelo trabalho artesanal e manual em oposição ao uso extensivo de maquinário, as feiras e mercados de produtos agrícolas e artesanais, etc.

Essa caracterização pode ser vista já nas primeiras páginas do romance. O primeiro habitante daquela sociedade com quem o protagonista tem contato é Dick, o barqueiro que o leva para se banhar no rio Tâmisa (em frente ao qual nosso protagonista reside) na primeira manhã em que

${ }^{6}$ Original: "He was a precocious reader, claiming to have started on the works of Sir Walter Scott at the age of four and to have completed the entire oeuvre by the time he was seven. Already he was highly receptive to medievalism and romance". 
acorda nesta sociedade. O traje de Dick, que não é muito diferente do que as outras pessoas daquela sociedade vestiam, é descrito da seguinte maneira:

[...] não parecia com nenhuma roupa moderna do dia-a-dia que eu tenha visto, mas serviria muito bem como uma fantasia para uma imagem da vida no século quatorze: era de tecido azul-escuro, razoavelmente simples, mas de material fino, e sem mancha alguma (MORRIS, 2007: 5) ${ }^{7}$.

Algumas páginas adiante, o protagonista descreve as casas que observa enquanto anda, junto com Dick, pelas ruas da Londres do século XXI. Eram elas sólidas, bonitas e com uma aparência campestre, sendo que a maioria era feita a partir de madeira e gesso, o que as tornava, por conta da forma como precisavam ser construídas com estes materiais,

[...] tão parecidas com as casas medievais de mesmo material que eu me senti como se estivesse vivo no século quatorze; uma sensação reforçada pelo traje das pessoas que encontrávamos ou pelas quais passávamos, em cujas vestimentas não havia nada de 'moderno' (MORRIS, 2007: $15)^{8}$.

${ }^{7}$ Original: "[...] was not like any modern work-a-day clothes I had seen, but would have served very well as a costume for a picture of fourteenth century life: it was of dark blue cloth, simple enough, but of fine web, and without a stain on it".

${ }^{8}$ Original: "[...] so like medieval houses of the same materials that I fairly felt as if I were alive in the fourteenth century; a sensation helped out by the costume of the people that we met or passed, in whose dress there was nothing "modern"'. 
As descrições que Morris faz dos trajes e dos edifícios e decorações nestas e em várias outras passagens da narrativa nos interessa por dois motivos: i) pela atenção aos detalhes desses elementos, o que se relaciona com a própria carreira e interesses pessoais do escritor (na arquitetura, nos tecidos, na decoração de interiores) e ii) pela inserção e valorização de determinados aspectos (a semelhança com o medievo e a relativa simplicidade do design combinada com a sua produção cuidadosa) nestas descrições, e frequente contraposição deles com aqueles que marcam a arquitetura e os trajes do período vitoriano.

Assim, William Morris estabelece uma comparação entre o seu tempo presente (o século XIX) e o tempo passado da idade média européia (da maneira como ele a idealizava) com certo saudosismo. Isto porque a sua sociedade comunista ideal, que tem um estilo de vida e de organização com características medievais, é colocada como muito melhor que a sociedade capitalista industrial do século XIX - melhor porque mais feliz, e mais feliz devido a um estilo de vida que combina aspectos comunistas com características da sociedade medieval.

Ademais, na narrativa, o escritor imagina que, nos primeiros anos que se seguiram ao processo revolucionário que deu origem àquela sociedade comunista, observou-se um grande êxodo urbano e grande ocupação das pequenas vilas rurais, constituindo uma realidade em que a grande maioria das pessoas estava concentrada no campo. Assim, a maioria dos antigos centros urbanos desapareceram junto com o modo de vida comercial e industrial; algumas dessas cidades maiores continuaram a 
existir (como foi o caso de Londres), mas foram profundamente transformadas pela influência do modo de vida do campo:

A cidade invadiu o campo; mas os invasores [...] sucumbiram à influência dos seus arredores, e tornaram-se pessoas do campo; e, por sua vez, à medida em que se tornavam mais numerosos que os citadinos, também os influenciaram; de modo que a diferença entre a cidade e o campo se tornava cada vez menor (MORRIS, 2007: 45) ${ }^{9}$.

Estas cidades que ainda existiam eram arborizadas, cheias de jardins e campos, dotadas de belas casas relativamente pequenas e simples, mas muito bem construídas, e locais de feiras que aconteciam todos os dias.

A caracterização da sociedade utópica como sendo marcadamente campestre é indicativa tanto da admiração do autor pelo estilo de vida medieval (também marcado pela predominância do campo sobre as cidades), como também da falta de entusiasmo de Morris com relação aos avanços tecnológicos dos séculos XVIII e XIX que marcaram a organização da sociedade burguesa industrial. Esta perspectiva é reforçada, ainda, pela sua preferência e valorização do trabalho artesanal em contraposição ao trabalho fabril e altamente mecanizado da Revolução Industrial.

9 Original: "The town invaded the country; but the invaders [...] yielded to the influence of their surroundings, and became country people; and in their turn, as they became more numerous than the townsmen, influenced them also; so that the difference between town and country grew less and less". 
Assim, a industrialização tem um caráter eminentemente negativo na obra, obviamente refletindo a perspectiva do seu próprio autor, que é expressa em praticamente todos os personagens da obra. A sua alta capacidade produtiva é vista como uma farsa, na medida em que Morris considera que os produtos dessas indústrias são feitos apenas para serem vendidos na maior quantidade possível e não são pensados para serem usufruídos. A suposta diminuição da necessidade do trabalho humano através da introdução de máquinas também é dispensada como falsa, pois o autor considera que os trabalhadores ficavam submetidos como 'escravos' das máquinas e de seu ritmo.

Talvez a única contribuição positiva da industrialização que possa ser destacada na perspectiva de Morris é a de ser a deflagradora de movimentações no sentido da revolução socialista - devido às condições de vida miseráveis que ela impõe, de forma direta ou indireta, à maioria da população. Na narrativa, o processo revolucionário que resultou na Inglaterra comunista, contado de forma detalhada pelo personagem Hammond, tem início a partir da percepção da classe trabalhadora de sua condição de explorados e, posteriormente, de sua união enquanto uma força política capaz de mudar a sociedade - processo que a teoria marxista, da qual Morris tira inspiração, entende como sendo a aquisição da consciência de classe pelo proletariado (MARX, 1998).

Neste sentido, chama atenção o fato de que Morris se preocupou em inserir, em sua narrativa de um socialismo utópico, uma explicação mais ou menos detalhada de como essa sociedade se constituiu - neste caso, através 
de um processo revolucionário cheio de luta e sofrimento, ao qual se seguiu uma reconstrução paulatina e laboriosa. Sobre isso, o escritor galês Raymond Williams escreve:

Mas o que é emergente na obra de Morris, e o que me parece cada vez mais a parte mais forte de Notícias de Lugar Nenhum, é a inserção crucial da transição para a utopia, que não é descoberta, encontrada ou projetada - nem mesmo, exceto no plano convencional mais simples, sonhada -, mas batalhada. Entre o escritor ou o leitor e essa nova condição há o caos, a guerra civil, a reconstrução lenta e dolorosa (WILLIAMS, 2011: 279).

Não por acaso, esta reconstrução pós-revolucionária engendrou uma organização social oposta à realidade industrializada do século XIX em praticamente todos os sentidos: afinal, foram os abusos das massas cometidos pela burguesia e Estado capitalistas que impulsionaram a causa revolucionária. É a aproximação desta nova organização social, a utopia de Morris, com o passado medieval europeu - como vimos acima - que parece surpreender.

Não obstante as semelhanças entre a sociedade utópica de Morris e o passado medieval, é importante destacar que esta sociedade possui uma série de características fundamentais que a diferencia de forma significativa deste período. A mais importante delas, que diferencia virtualmente esta sociedade também de qualquer outra da história humana, é a inexistência da propriedade privada, abolida pela revolução que instaurou aquela forma de vida. As terras são trabalhadas de forma cooperativa e pelo bem comum 
(Commonwealth), sem as relações de dependência entre pessoas em condições sociais desiguais; os que se dedicam ao artesanato e à construção de casas e estradas o fazem também pelo bem comum, e qualquer produto de que se tenha necessidade ou desejo de consumir (desde roupas e comida até tabaco e vinho) pode ser adquirido nas feiras e mercados, sem a necessidade de se dar algo em troca (nem outros produtos e nem moedas, as quais se tornaram meros itens de coleção).

Neste sentido, todas as atividades de labor necessárias para a comunidade - a agricultura, o artesanato, a construção - são feitas por indivíduos que querem exercer estas atividades. E eles as querem pois, na perspectiva dos habitantes desta sociedade (que é a perspectiva de Morris), o trabalho é uma atividade prazerosa, tanto por exercitar corpo e mente como por beneficiar, em maior ou menor medida, o coletivo. No entanto, ainda nesta perspectiva, o trabalho só poderia ser prazeroso caso o trabalhador tivesse total controle sobre o processo produtivo - ou seja, na sociedade capitalista, a divisão do trabalho e a submissão dos trabalhadores ao ritmo das máquinas faziam do trabalho algo indesejável e desprazeroso.

Sobre a questão da divisão do trabalho, Shaw (1992: 29) explicita bem a perspectiva de nosso autor: "Em suma, Morris via a divisão do trabalho como o produto de uma sociedade que era incapaz de se humanizar e de mudar as condições de seu trabalho. Divisão do trabalho e capitalismo eram inseparáveis [...]"10. No que diz respeito à mecanização,

${ }^{10}$ Original: "In short, Morris saw the division of labour as a product of a society that was incapable of humanising itself and changing the conditions of its work. Divided labour and capitalism were inseparable [...]". 
ainda que dê um grande valor ao trabalho artesanal e manual, nosso autor não recusa completamente o uso das máquinas. Segundo Williams (1969), Morris acreditava que o culpado pela eliminação do prazer em trabalhar no século XIX não eram as máquinas, mas sim a lógica de produção capitalista mecanizada, que impunha aos trabalhadores o ritmo das máquinas:

Sei que algumas pessoas cultas, de espírito artístico, têm as máquinas como particularmente desagradáveis [...] [mas] permitir que elas sejam nossos donos e não nossos servos é o que destrói, hoje em dia, a beleza da vida (MORRIS apud WILLIAMS, 1969: 166).

Apesar de haver pessoas especializadas em determinados tipos de trabalho - como Philippa, a personagem que aparece, num breve capítulo, como a melhor escultora de uma equipe que construía uma casa -, cada um é livre para executar e aprender outros tipos de atividade que lhes pareçam desejáveis - como é o caso de Dick, que é tanto um remador quanto um artesão metalúrgico.

Por ser motivado pela necessidade dos membros da comunidade e não pela lógica mercantilista nem capitalista de outros períodos, o trabalho produz apenas a quantidade suficiente para cobrir esta necessidade (o que significa que não há desperdício de materiais e de horas de trabalho), qualquer tipo de trabalho que por ventura der muitos problemas é abandonado e a comunidade passa tranquilamente a viver sem o seu produto. 
Alguns capítulos depois das conversas entre Hammond e o protagonista, este se encontra numa pequena viagem junto a um grupo de amigos (o casal Dick e Clara, e Ellen, a jovem por quem ele se apaixona) para participar da colheita de trigo no interior. Durante a estadia do grupo na casa de um velho e inteligente homem (o personagem Henry Morsom), nos é revelado através da explicação deste personagem que, ao longo do período logo após a vitória da revolução que instaurou o modo de vida socialista na Inglaterra, os habitantes da nova sociedade foram, aos poucos, deixando para trás as máquinas e instrumentos que não lhes pareciam úteis ou desejáveis.

As máquinas e instrumentos considerados úteis, em contrapartida, continuaram a ser utilizados, passando por profundos aprimoramentos e sendo colocados a serviço dos trabalhadores - ou para melhorar a qualidade de seu trabalho para que executassem as atividades que não eram agradáveis de serem feitas à mão. Sobre isso, o personagem Hammond já havia explicado ao nosso protagonista: "Todo trabalho que seria irritante de se fazer à mão é feito por máquinas imensamente aprimoradas; e todo trabalho prazeroso de ser feito à mão é feito sem máquinas" (MORRIS, 2007: 61) $)^{11}$.

Outra característica fundamental desta sociedade é a ausência de qualquer tipo de entidade política que concentre poderes: a população se organiza em pequenas unidades administrativas locais (comunas), as quais

\footnotetext{
11 Original: "All work which would be irksome to do by hand is done by immensely improved machinery; and in all work which it is a pleasure to do by hand machinery is done without".
} 
se reúnem regularmente em assembléias ${ }^{12}$ onde se discute qualquer questão trazida pelos seus membros (a construção de uma nova ponte ou a demolição de casas ou edifícios inconvenientes, por exemplo). Essas questões, se for o caso, são decididas através de votação por maioria absoluta - constituindo, assim, um sistema de democracia direta a níveis locais. Ademais, Hammond indica que a revolução que instituiu aquele sistema comunista se espalhou para todas as outras partes do mundo, abolindo os Estados nacionais e constituindo este modo de organização sócio-econômica comunista e de democracia direta nas outras regiões do globo (muitas das quais, como no caso da América do Norte, ainda estavam se reconstruindo). Ou seja, não havia conflitos nem a nível local, nem a nível inter-regional, na medida em que a abolição da propriedade privada — e, com ela, da dominação de uma classe por outras - significou o fim dos motivos que geram essas tensões.

Assim, neste modo de organização sociedade do século XXI de Morris, tudo é feito pela comunidade e para a comunidade em benefício comum, cada um faz aquilo que lhe der vontade, e essa vontade será, quase sempre, inspirada pelo desejo de contribuir com o bem comum.

No último capítulo, a narrativa assume um caráter de inspiração. Quando estava prestes a participar de um banquete numa pequena igreja no campo, junto com os seus companheiros Dick, Clara e Ellen, o protagonista

\footnotetext{
${ }^{12}$ De acordo com o personagem Hammond, os habitantes daquela sociedade dão a estas assembléias ordinárias o nome de Mote, o qual, ainda de acordo com ele, vem da "antiga língua dos tempos antes da burocracia" (cf. MORRIS, 2007: 56). Trata-se do inglês antigo (do período medieval).
} 
se vê transportado de volta para a sua realidade, no século XIX. A partir daí, ele tem uma reflexão sobre tudo o que viu e experimentou naquele "sonho", numa passagem que parece pretender comover e entusiasmar o leitor a acreditar que é possível se constituir uma sociedade tal como a obra descreve - feliz, sem a exploração do homem pelo homem e sem os conflitos inerentes às desigualdades sociais - , de modo que o "sonho" do protagonista poderia se tornar uma visão real do futuro.

Para tanto, Morris dá a entender que seria preciso que o leitor e os seus contemporâneos enxergassem que uma sociedade melhor do que a que se vive é desejável e possível por meio do reconhecimento da exploração da classe trabalhadora pela classe dominante e da insurreição daquela contra esta.

\section{Considerações finais}

As comparações que William Morris estabelece entre o contexto do século XIX em que ele viveu e um futuro comunista que ele imagina como ideal, no fundo, são também um saudosismo do autor em relação ao passado medieval, na medida em que a sua projeção de um futuro ideal possui uma série de características que retomam o medievo (como a predominância da vida rural e do trabalho manual artesanal). No entanto, a inserção de uma série de outros aspectos que Morris considera fundamentais para a felicidade da sociedade, como a abolição da propriedade privada e a instituição de um modo de vida pautado pelo cooperativismo, dá à sociedade utópica do autor uma originalidade muito 
própria, que traduz bem as suas angústias em relação ao tempo em que ele vivia e os seus anseios por uma sociedade nova e ideal.

A retrospectiva temporal que o personagem Hammond fornece ao protagonista no capítulo X é uma ótima ilustração da maneira como Morris reconstitui o passado e o presente da sociedade em que vivia, assim como a maneira como ele espera que ela venha a se constituir no futuro:

\begin{abstract}
A Inglaterra já foi um país de clareiras entre os bosques e campos, com algumas cidades intercaladas, as quais eram fortalezas para o exército feudal, mercados para o povo, locais de aglomeração para os artesãos. Ela então se tornou um país de enormes e abomináveis fábricas e covis de apostas mais abomináveis ainda, cercados de uma fazenda negligenciada e empobrecida, pilhada pelos mestres das fábricas. Ela é agora um jardim, onde nada é desperdiçado e nada é estragado, com as moradias, galpões e oficinas necessárias espalhadas país afora, tudo aparado e arrumado e belo (MORRIS, 2007: 45) ${ }^{13}$.
\end{abstract}

\title{
Referências
}

DUBY, Georges. Guerreiros e camponeses: os primórdios do crescimento econômico europeu do século VII ao século XI. Tradução de Elisa Pinto Ferreira. Lisboa: Estampa, 1980.

\footnotetext{
${ }^{13}$ Original: "England was once a country of clearings amongst the woods and wastes, with a few towns interspersed, which were fortresses for the feudal army, markets for the folk, gathering places for the craftsmen. It then became a country of huge and foul workshops and fouler gambling-dens, surrounded by an ill-kept, poverty-stricken farm, pillaged by the masters of the workshops. It is now a garden, where nothing is wasted and nothing is spoilt, with the necessary dwellings, sheds and workshops scattered up and down the country, all trim and neat and pretty".
} 
ENGELS, Friedrich; MARX, Karl. A ideologia alemã. Introdução de Jacob Gorender. Tradução de Luiz Claudio de Castro e Costa. $2^{a}$ ed. São Paulo: Martins Fontes, 1998.

LE GOFF, Jacques. A civilização do ocidente medieval. Tradução de Manuel Ruas. $2^{\mathrm{a}}$ ed., vol. 1. Lisboa: Editorial Estampa, 1995.

MACCARTHY, Fiona. Morris, William (1834-1896). Oxford Dictionary of National Biography, Oxford, p. 1-17, set. 2004. Disponível em: $<$ https://www.oxforddnb.com/view/10.1093/ref:odnb/9780198614128.001. 0001/odnb-9780198614128-e-19322? print=pdf > . Acesso em: 18 ago. 2019.

MORRIS, William. News from Nowhere, or An Epoch of Rest, being some chapters from A Utopian Romance. Transcrição feita por David Price a partir da edição de Longmans, Green, and Co. de 1908. Project Gutenberg, 2007, ebook. Disponível em: $<$ https://www.sfu.ca/ poitras/Morris_News-from=Nowhere $>$. Acesso em: 18 ago. 2019.

SHAW, Christopher. The Idea of Work in "News from Nowhere". Journal of William Morris Studies, Washington, v. 9, n. 3, p. 19-30, 1992. Disponível em: $<$ http://www.morrissociety.org/morris/socialJournalArticles.html $>$. Acesso em: 18 ago. 2019.

THOMPSON, Edward. P. A formação da classe operária inglesa. Tradução de Renato Busatto Neto e Cláudia Rocha de Almeida. $2^{\mathrm{a}}$ ed. Rio de Janeiro: Paz \& Terra, 2012.

WILLIAMS, Raymond. Arte e sociedade. In: - Cultura e sociedade. Tradução de Leônidas H. B. Hegenberg, Octanny Silveira da Mota e Anísio Teixeira. São Paulo: Companhia Editora Nacional, 1969. pp. 145-169. 
Cadernos de Clio, Curitiba, v. 10, nº. 2, 2019

Utopia e ficção científica. In: - Cultura e materialismo. Tradução de André Glaser. São Paulo: Editora UNESP, 2011. pp. 267-291.

Recebido em: 19/08/2019

Aceito em: 03/02/2021 